\title{
PEMETAAN INDEKS MASSA TUBUH DAN LINGKAR PINGGANG SEBAGAI INDIKATOR OBESITAS DI KALANGAN MAHASISWA
}

\author{
Alexander Halim Santoso ${ }^{1}$, Idawati Karjadidjaja ${ }^{2}$, Olivia Charissa ${ }^{3}$ \\ ${ }^{1}$ Bagian Ilmu Gizi, Fakultas Kedokteran, Universitas Tarumanagara, Jakarta \\ Email: alexanders@fk.untar.ac.id; dr.alexsantoso@gmail.com \\ ${ }^{2}$ Bagian Ilmu Gizi, Fakultas Kedokteran, Universitas Tarumanagara, Jakarta \\ Email: idak@fk.untar.ac.id \\ ${ }^{3}$ Bagian Ilmu gizi, Fakultas Kedokteran, Universitas Tarumanagara, Jakarta \\ Email: charissa.olivia@gmail.com
}

\begin{abstract}
ABSTRAK
Latar belakang: Obesitas adalah salah satu masalah kesehatan dunia di mana diperkirakan ada lebih dari tiga ratus juta penduduk dunia yang mengalami obesitas. Berdasarkan data dari Riset Kesehatan Dasar (Riskesdas) 2013, prevalensi gemuk pada remaja (16-18 tahun) adalah 7,3\% dimana 1,6\% nya merupakan obesitas. Mahasiswa yang tergolong ke dalam kelompok remaja cenderung lebih banyak duduk, jarang berolahraga dan pola makannya kurang baik. Kondisi ini menyebabkan mahasiswa berpotensi menderita obesitas. Metode: Penelitian ini merupakan penelitian deskriptif dengan disain potong-lintang. Penelitian ini ditujukan untuk mendapatkan gambaran yang lebih jelas mengenai prevalensi obesitas di kalangan mahasiswa FK UNTAR. Penelitian dilakukan pada bulan September 2016 di Kampus I UNTAR, yang melibatkan 231 mahasiwa FK UNTAR angkatan 2016 berusia 15-21 tahun meliputi pengisian kuesioner dan pengukuran Berat Badan (BB), Tinggi Badan (TB), dan Lingkar Pinggang (LP). Mahasiswa yang mengikuti penelitian sebelumnya menanda tangani informed consent. Hasil: Didapatkan sebagian besar subjek berusia 18 tahun $(67,4 \% ; 17.87 \pm 0,71)$ dengan sebagian besar $(70,4 \%)$ adalah perempuan. Berdasarkan pengukuran Indeks Massa Tubuh (IMT), didapatkan 26,1\% subjek menderita obesitas. Sebanyak 61,5\% subjek laki-laki dan 82,9\% subjek perempuan beresiko obesitas sentral. Kesimpulan: Pada penelitian ini didapatkan lebih dari seperempat mahasiswa Fakultas Kedokteran UNTAR angkatan 2016 menderita menderita obesitas dan lebih dari limapuluh persen beresiko terhadap obesitas sentral. Diperlukan penelitian lanjutan untuk dapat melihat faktor-faktor yang berperan terhadap obesitas di kalangan mahasiswa.
\end{abstract}

Kata kunci: obesitas, remaja, mahasiswa, indeks massa tubuh, lingkar pinggang

\section{PENDAHULUAN}

Obesitas adalah salah satu masalah kesehatan di dunia dan seiring meningkatnya taraf kesejahteraan masyarakat. Diperkirakan lebih dari sepertiga penduduk dunia yang mengalami obesitas.(Hruby, 2015) Berdasarkan indeks massa tubuh (IMT), untuk orang Asia dinyatakan obesitas bila IMT $\geq 25 \mathrm{~kg} / \mathrm{m}^{2}$.(WHO, 2000a) Hasil penelitian epidemiologi menunjukkan hubungan langsung antara IMT $\geq 30$ dengan resistensi insulin dan penyakit-penyakit metabolik seperti diabetes, hipertensi dan penyakit jantung koroner.(Klein, 2007; Lofgren, 2004) Obesitas disebabkan oleh asupan makanan yang berlebihan dan kurangnya aktivitas fisik.(Tateya, 2013) Perilaku makan yang tidak sehat berhubungan erat dengan timbulnya masalah kesehatan di usia lanjut.(Bas, 2005; Naeeni, 2014)

Jumlah remaja di Amerika yang mengalami obesitas semakin meningkat, dari 16,9\% pada periode tahun 2010-2012 menjadi 20,5\% selama 2011-2014.(Ogden, 2014, 2015) Berdasarkan data dari Riset Kesehatan Dasar (Riskesdas) 2013, prevalensi gemuk pada remaja (16-18 tahun) adalah 7,3\% di mana 1,6\% nya merupakan obesitas. Dibandingkan tahun 2007, prevalensi gemuk naik dari $1,4 \%$ menjadi $7,3 \%$ di tahun 2013. Daerah khusus ibukota (DKI) Jakarta merupakan provinsi dengan prevalensi gemuk tertinggi $(4,2 \%)$ dibandingkan provinsi lainnya di Indonesia.(RI, 2013)

Kelompok mahasiswa merupakan kelompok remaja yang rentan terhadap obesitas. Selain perubahan pola hidup, seperti duduk terlalu lama, jarang berolahraga, merokok, mahasiswa juga cenderung memilih makanan siap saji, tidak cukup mengonsumsi buah dan sayur.(Ozkok, 2015) 
Pemayun (2015) mendapatkan prevalensi obesitas di kelompok mahasiswa kedokteran sebesar 16,6\%.(Pemayun, 2014) Penelitian ini hendak melihat berapa prevalensi obesitas pada mahasiswa Fakultas Kedokteran Universitas Tarumanagara.

\section{METODE PENELITIAN}

Penelitian ini merupakan penelitian deskriptif dengan disain cross-sectional. Subjek diberi penjelasan mengenai penelitian dan kemudian dimintakan informed consent secara tertulis. Pengumpulan data dilakukan dengan mengisi kuesioner dan melakukan pengukuran berat badan (BB), tinggi badan (TB) dan lingkar pinggang (LP).

Pengukuran berat badan dilakukan dalam keadaan kandung kemih kosong, belum makan, tidak menggunakan pakaian tebal, tidak menggunakan perhiasan (jam tangan, ban pinggang), tidak menggunakan alas kaki dan tidak membawa benda-benda lain dalam kantong baju. Subjek berdiri tegak, keadaan rileks, kedua lengan bebas di samping badan, pandangan mata lurus ke depan. Penimbangan dilakukan sebanyak 2 kali dengan hasil penimbangan ulang tidak berbeda $0,1 \mathrm{~kg}$. Penimbangan menggunakan alat timbangan manual (SECA 762-Mechanical Floor Scale).

Pengukuran tinggi badan (TB) dilakukan dengan alat pengukur microtoise stature meter yang sudah ditera. Microtoise ditempelkan pada permukaan yang rata, keras dan tegak lurus terhadap permukaan. Subjek yang akan diukur berdiri tegak, tidak menggunakan alas kaki, keadaan rileks, kedua lengan bebas berada di samping tubuh, pandangan mata lurus ke depan dengan acuan meatus acusticus externus dan ujung mata berada pada satu garis lurus. Kepala bagian belakang, tulang belikat, pinggul, otot betis dan tumit menempel pada permukaan dinding. Seluruh perhiasaan pada kepala (sanggul, ikatan rambut) dilepaskan sebelum pengukuran. Pengukur menurunkan microtoise hingga tepat menyentuk bagian atas kepala. Pengukuran dilakukan sebanyak 2 kali dengan hasil penimbangan ulang tidak berbeda $0,1 \mathrm{~cm}$.

Pengukuran lingkar perut (LP) dilakukan dengan menggunakan alat ukur SECA 201, subjek berdiri tegak, perut rileks, kedua lengan tergantung bebas disamping tubuh, kedua kaki rapat, dan tidak menggunakan alas kaki. Fisik pengukuran LP adalah antara bagian bawah dari arcus costae dengan bagian atas crista iliaca pada garis mid-aksilaris. Pengukur melingkari pinggang subjek dengan pita pengukur. Pengukuran dilakukan 2 kali, dengan hasil pengukuran tidak berbeda $0,1 \mathrm{~cm}$.

\section{Uji Statistik}

Data karakteristik diolah menggunakan perangkat lunak Statistical Program for Social Science (SPSS) versi 20 dan disajikan dalam bentuk n (\%).

\section{HASIL DAN PEMBAHASAN}

\section{Karakteristik Subjek}

Sebanyak 233 subjek yang diukur, didapatkan 69 laki-laki (29,6\%) dan 164 (70,4\%) perempuan dengan lebih dari separuh jumlah subjek berusia 18 tahun $(67,4 \%)$ (Tabel 1). Satu orang subjek berusia 15 tahun merupakan subjek yang menjalani program akselerasi. Pemayun (2014) berdasarkan hasil penelitiannya menunjukkan keadaan yang sama dimana didapatkan jumlah subjek perempuan (73\%) lebih banyak dibandingkan subjek laki-laki (26,6\%).(Pemayun, 2014) McKinstry melaporkan bahwa jumlah subjek perempuan yang mengambil pendidikan 
Kedokteran juga meningkat di negara-negara seperti Inggris, Amerika, Kanada dan Australia.(McKinstry, 2008)

Tabel 1. Sebaran Karakteristik Subjek

\begin{tabular}{llc}
\hline No & Data & $\mathrm{n}(\%)$ \\
\hline 1. & Jenis Kelamin & \\
& Laki-laki & $69(29,6 \%)$ \\
& Perempuan & $164(70,4 \%)$ \\
2. & Usia (tahun) & \\
15 & $1(0,4 \%)$ \\
16 & $6(2,6 \%)$ \\
17 & $45(19,3 \%)$ \\
18 & $157(67,4 \%)$ \\
19 & $16(6,9 \%)$ \\
20 & $5(2,1 \%)$ \\
\hline
\end{tabular}

\section{Pengukuran Indeks Massa Tubuh (IMT)}

Berdasarkan pengukuran IMT, didapatkan 61 subjek tergolong ke dalam obesitas $(26.1 \%)$ (Tabel 2). Nilai tersebut lebih tinggi dibandingkan nilai yang didapatkan oleh Pemayun dimana $16,6 \%$ subjek tergolong obese.(Pemayun, 2014) Pada penelitian ini didapatkan juga jumlah subjek perempuan $(n=35)$ yang mengalami obesitas lebih besar dibandingkan subjek laki-laki $(n=26)$. Obesitas merupakan kondisi akumulasi lemak berlebihan di dalam jaringan adiposa yang disebabkan oleh karena asupan makanan berenergi tinggi dan rendahnya aktivitas fisik.(Sparling, 2007; WHO, 2000b) Menurut Nelson et al, mahasiswa, yang digolongkan ke dalam kelompok dewasa muda (18-25 tahun), mengalami perubahan dalam banyak hal, meliputi diet dan pola aktivitas harian.(LA, 2008) Sparling dan Plotnikoff et al menyampaikan bahwa sebagian besar mahasiswa kurang mengonsumsi buah dan sayuran dan hanya 6 dari 10 mahasiswa yang melaksanakan aktivitas fisik lebih dari 3 kali per minggu secara rutin.(Plotnikoff Ronald C; Costigan Sarah A; Williams, 2015; Sparling, 2007) Plotnikoff et al selanjutnya melaporkan bahwa mahasiswa memiliki kebebasan lebih tinggi dalam memilih jenis makanan yang hendak dikonsumsi dan kurang memikirkan risko timbulnya penyakit tidak menular pada saat memilih makanan.(Plotnikoff Ronald C; Costigan Sarah A; Williams, 2015) Nelson et al juga melaporkan bahwa lamanya aktivitas fisik mahasiswa perempuan cenderung menurun per minggu nya, dan pada kelompok mahasiswa laki-laki, aktivitas di waktu senggang seperti bermain komputer meningkat dari 10,4 jam menjadi 14,2 jam per minggunya.(Nelson, 2006) IMT merupakan alat skrining obesitas yang nyaman, aman dan murah untuk suatu populasi. Pengukuran IMT tidak dapat membedakan antara massa bebas lemak dan massa lemak yang ada di dalam tubuh.(Nuttall, 2015; Shah, 2012) 
Tabel 2. Sebaran Subjek Penelitian Berdasarkan Status Gizi

\begin{tabular}{llccccc}
\hline No. Status Gizi & $\begin{array}{c}\text { Mahasiswa } \\
\text { Laki-laki } \\
(\mathrm{n}, \%)\end{array}$ & $\begin{array}{c}\text { Mahasiswa } \\
\text { Laki-laki } \\
(\mathrm{n}, \mathrm{SD})\end{array}$ & $\begin{array}{c}\text { Mahasiswa } \\
\text { Perempuan } \\
(\mathrm{n}, \%)\end{array}$ & $\begin{array}{c}\text { Mahasiswa } \\
\text { Perempuan } \\
(\mathrm{n}, \mathrm{SD})\end{array}$ & $\begin{array}{c}\text { Total } \\
\text { Mahasiswa } \\
(\mathrm{n}, \%)\end{array}$ \\
\hline & IMT & $\begin{array}{c}24,09(\mathrm{SD} \\
2,95)\end{array}$ & $5,23)$ & $35(15 \%)$ \\
1. & Kurang & $7(10,1 \%)$ & & $27(16,5 \%)$ & $102(43,8 \%)$ \\
2. & Normal & $29(42,0 \%)$ & $73(44,5 \%)$ & $35(15 \%)$ \\
3. & Lebih & $7(10,1 \%)$ & $28(17,1 \%)$ & $32(13,7 \%)$ \\
4. & Obese 1 & $15(21,7 \%)$ & $17(10,4 \%)$ & $29(12,4 \%)$ \\
5. & Obese 2 & $11(15,9 \%)$ & $18(11,0 \%)$ & \\
\hline
\end{tabular}

\section{Pengukuran Lingkar Pinggang}

Sebanyak 17 (24,6\%) subjek laki-laki memilki lingkar pinggang di atas $90 \mathrm{~cm}$, dan $38(23,2 \%)$ subjek perempuan memiliki lingkar pinggang di atas $80 \mathrm{~cm}$ (Tabel 3). Bila dihubungkan dengan IMT $\geq 25$, didapatkan $61,5 \%$ subjek laki-laki dan $82,9 \%$ subjek perempuan yang memiliki lingkar pinggang di atas nilai normal (Tabel 4). Subjek laki-laki dengan lingkar pinggang di atas $90 \mathrm{~cm}$ dan perempuan dengan lingkar pinggang di atas $80 \mathrm{~cm}$ beresiko terhadap obesitas sentral. Bronkowska et al melaporkan pada penelitian yang melibatkan remaja usia 17-18 tahun, didapatkan $25,6 \%$ remaja perempuan dan $15,6 \%$ remaja laki-laki mengalami obesitas sentral.(Biernat, 2015). Obesitas sentral merupakan salah satu faktor resiko terjadinya resistensi insulin dan penyakit kardiovaskular.(WHO, 2011)

Tabel 3. Sebaran Subjek Penelitian Berdasarkan Lingkar Pinggang

\begin{tabular}{llc}
\hline No & Data & $\mathrm{n}(\%)$ \\
\hline 1. & Laki-laki & \\
& $<90 \mathrm{~cm}$ & $52(75,4 \%)$ \\
& $\geq 90 \mathrm{~cm}$ & $17(24,6 \%)$ \\
2. & Perempuan & $126(76,8 \%)$ \\
& $<80 \mathrm{~cm}$ & $38(23,2 \%)$ \\
\hline
\end{tabular}

Tabel 4. Sebaran Subjek Penelitian Berdasarkan Resiko Obesitas Sentral

\begin{tabular}{llc}
\hline & & $\begin{array}{c}\text { IMT } \geq 25 \\
\mathrm{n}(\%)\end{array}$ \\
\hline 1. & Lingkar Pinggang & \\
& Laki-laki & \\
& $<90 \mathrm{~cm}$ & $10(38,5 \%)$ \\
& $\geq 90 \mathrm{~cm}$ & $16(61,5 \%)$ \\
2. & Lingkar Pinggang & \\
& Perempuan & \\
& $<80 \mathrm{~cm}$ & $6(17,1 \%)$ \\
& $\geq 80 \mathrm{~cm}$ & $29(82,9 \%)$ \\
\hline
\end{tabular}




\section{KESIMPULAN DAN SARAN}

\section{Kesimpulan}

Berdasarkan hasil pemeriksaan antropometri (berat badan dan tinggi badan) ditemukan lebih dari seperempat jumlah mahasiswa Fakultas Kedokteran UNTAR angkatan 2016 mengalami obesitas dan bila digabungkan dengan pengukuran lingkar pinggang ditemukan lebih dari lima puluh persen beresiko obesitas sentral.

\section{Saran}

Pengamatan ini hanya dilakukan pada satu angkatan mahasiswa, oleh karena itu perlu dilakukan penelitian lebih lanjut yang meliputi mahasiswa Fakultas Kedokteran dari beberapa angkatan. Disamping itu perlu diteliti lebih dalam untuk mengetahui faktor-faktor apa saja yang berperan terhadap obesitas pada mahasiswa Fakultas Kedokteran. Untuk mahasiswa yang obesitas, perlu dilanjutkan dengan studi Kohort untuk menilai perkembangan secara alami.

\section{REFERENSI}

Bas, M.; Altan, T.; Dincer, D.; Aran, E.; Kaya, HG.; Yuksek, O. (2005). Determination of dietary habits as a risk factor of cardiovascular heart disease in Turkish adolescents. European Journal of Nutrition, 44, 174-182.

Biernat, Bronkowska M; Bronlecka A; Plotrowska E; Wyka J;. (2015). Nutrition and Waist Circumference as an Indicator of Abdominal Obesity in 17-18 Year Old Youth. Journal of Nutrition and Food Sciences, 5(5), 5.

Hruby, A; Hu, Frank B. (2015). The Epidemiology of Obesity: A Big PIcture. Phamcoeconomics, 33(7), 673-689.

Klein, S.; Allison, DB.; Heymsfield, SB.; Kelley, DE.; Leibel, RL.; Nonas, C.; Khan, R. (2007). Waist circumference and cardiometabolic risk: a consensus statement from Shaping America's Health: Association for Weight Management and Obesity prevention; NAASO, The Obesity Society; the American Society for Nutrition and the America Diabetes Association. American Journal of Clinical Nutrition, 85, 1197-1202.

LA, Nelson MC; Story M; Larson NI; Neumark-Sztainer D; Lytle. (2008). Emerging adulthood and college-aged youth: an overlooked age for weight related behaviour change. Obesity, 16(10), 22052211.

Lofgren, I; Herron, K; Zern, T; West, K; Patalay, M; Shachter, NS; Koo, Sung I; Frenande, ML. (2004). Waist circumference is a better predictor than body mass index of coronary heart disease in overweight premenopausal women. The Journal of Nutrition, 134, 1071-1076.

McKinstry, Brian. (2008). Are there too many female medical graduates? Yes. BMJ, 336(7647), 748-749.

Naeeni, MM.; Jafari, S.; Fouladgar, M.; Heidari, K.; Farajzadegan, Z.; Fakhir, M.; Karami, P.; Omidi, R. (2014). Nutritional knowledge, practice and dietary habits among school children and adolescents. International Journal of Preventive Medicine, 5 (Suppl 2), S171-S178.

Nelson, Melissa C; Neumark-Stzainer, Dianne; Hannan, Peter J; Sirard, John R; Story, Mary. (2006). Longitudinal and secular trends in physical activity and sedentary behaviour during adolescence. Pediatrics, 118(6), 1627-1634.

Nuttall, Frank Q. (2015). Obesity, BMI, and Health: A Critical Review. Nutrition Research, 50(3), 117 128.

Ogden, Cynthia L; Carroll, Margaret D; Fryar, Cheryl D; Flegal, Katherine M. (2014). Prevalence of Childhood and Adult Obesity in the United States, 2011-2012. JAMA, 26(311), 8.

Ogden, Cynthia L; Carroll, Margaret D; Fryar, Cheryl D; Flegal, Katherine M. (2015). Prevalence of Obesity Amoing Adulths and Youth: United States, 2011-2014. NCHS Data Brief(209), 8.

Ozkok, GA. (2015). Evaluation of dietary habits among universitu students in Konya, Turkey. International Journal of Nutrition and Food Sciences, 4(4), 431-438. 
Pemayun, Tjokorda IRP; Saraswati, I Made Ratna. (2014). Gambaran kebiasaan mengonsumsi makanan cepat saji dan obesitas pada mahasiswa semester V program studi kedokteran umum Universitas Udayana tahun 2014. Intisari Sains Medis, 4(1), 6-13.

Plotnikoff Ronald C; Costigan Sarah A; Williams, Rebecca L; Hutchesson, Melinda J; Kennedy, Sarah G; Robards, Sara L; Allen, Jennifer; Collins, Clare E; Callister, Robin; Germov John. (2015). Effectiveness of intervemntions targetting physical activity, nutrition and healthy weight for university and college students: a systematic review and meta analysis. International Journal of Behavioral Nutrition and Physical Activity, 12(45).

RI, Badan Penelitian dan Pengembangan Kesehatan Kementerian Kesehatan. (2013). Riset Kesehatan Dasar (Riskesdas) 2013

Shah, Nirav R; Braverman, Eric R. (2012). Measuri g adiposity in patients: the utility of body mass index (BMI), percent body fat, and leptin. Plos One, 7(4), 8.

Sparling, Philip B. (2007). Obesity on Campus. Prevention Chronic Disease, 4(3), A72.

Tateya, Sanshiro; Kim, Francis; Tamori, Yoshikazu. (2013). Recent advances in obesity-induced inflammation and insulin resistance. Frontiers in Endocrinology, 4(93), 1-14. doi10.3389/fendo.2013.00093

WHO. (2000a). The Asia-Pacific perspective: redefining obesity and its treatment $\mathrm{S}$; Zimmet Innoue, $\mathrm{P}$ (Ed.)

WHO. (2000b). Obesity: Preventing and Managing the Global Epidemid WHO Technical Report Series (pp. 253). Geneva.

WHO. (2011). Waist circumference and waist-hip-ration: a report of a WHO expert consultation. 